\title{
Description of a Treatment Manual for in virtuo Exposure with Specific Phobia
}

\author{
Stéphane Bouchard, Geneviève Robillard, \\ Serge Larouche and Claudie Loranger
}

Additional information is available at the end of the chapter

http://dx.doi.org/10.5772/46417

\section{Introduction}

The DSM-IV-TR [1] defines a specific phobia as an intense and persisting fear that is excessive or irrational, usually triggered by the presence or the anticipation of a specific object or situation. The exposure to the fear-provoking object triggers an immediate and almost systematic anxious reaction that can take the form of a panic attack. The individual recognizes the excessive or irrational nature of his fear but avoids the situations that might put him in the presence of the fear-provoking stimulus or experiences these situations with a lot of anxiety. The avoidance and apprehension that are linked to the phobia impair the individual's daily functioning.

There are three important psychological components involved in the panic reaction of individuals suffering from phobias: thoughts, emotions and behaviour. Thought expresses how the patient interprets the stimulus. Thoughts are the first step of the anxious process, and two people could have different reaction in front of the same situation. In order for a situation to trigger anxiety, the person must consider the stimulus as dangerous, threatening or, in the case of some phobias, disgusting (e.g., worms). Second, the emotion is the panic itself. A panic attack is associated with many objective physiological reactions (e.g., cardiac palpitations, nausea, weak knees) which are traditional consequences of an increase in arousal, except in the case of blood-injuries subtype of phobias where a vasovagal response may lead to fainting [2]. Third, behaviour refers to the way people act following perceived threat. When danger is real, a simple and effective solution might require fighting or fleeing [3]. Avoiding the fear-provoking stimulus is a tempting solution, but in the case of phobias, it becomes a trap. If one avoids something that is not a real danger, how can one realise that danger is not real? In fact, avoidance is the key behaviour contributing to maintain anxiety and phobias. Avoidance can take many forms, from obvious behaviours such as refusing to visit someone who owns a dog to subtle behaviours such as carrying a rabbit foot for good 
luck. Avoidance is also referred to as safety seeking behaviour (i.e., a snake phobic taking a walk in a park could be proactively and continuously looking at the grass and scanning the surroundings) to highlight the fact that avoidance refers to the process of avoiding the occurrence of the feared consequence and aiming for safety, as opposed to the overt behaviour of moving away from the stimuli. In some instances, avoidance is also described as neutralization, when the phobic person tries to perform behaviours to reduce anxiety (e.g., asking for reassurance) or engage in mental processes in order to prevent to occurrence of the feared consequence. No matter how avoidance is called in the literature, the long term consequence is that avoidance prevents the phobic individual to develop mental representations of the stimuli that are associated with safety and with a sense of perceived control and self-efficacy, as opposed to perceived threat or disgust [3-9].

The recommended empirically supported treatment for phobias is CBT [10], and for specific phobia the key therapeutic technique is exposure. In the dictionary of behavioural interventions, Marshall [11] defines exposure as every procedure that confronts the individual to a stimulus generating an undesired behaviour or emotional response. There are many ways to face one's fears, from imaginary exposure to exposure in real situations («in vivo $»$ ) $[12,13]$. To be effective, the treatment cannot blindly and solely rely on exposure; it must also include basic elements that will not be discussed in this chapter, such as a sound and individualized case formulation, a healthy and constructive therapeutic alliance, a competent therapist and an exposure plan that is well dosed and controls avoidance adequately (for more details, see [4,6-9,12-15]).

Traditional exposure techniques have some limits [15-16], such as potential breach in confidentiality during exposure in a public place, the lack of control over the stimuli in many exposure situations (e.g., traffic on a highway or behaviour of an animal), the financial costs associated with some stimuli (e.g., cost of flying tickets for the patient and the therapist in the treatment of flying phobia), the need to care for and feed reptiles or insects, the possibility of unexpected events (e.g., the elevator is out of order or jams), the impossibility to reproduce and graduate some stimuli at will (e.g., thunderstorms), etc. Fortunately, these limits stimulated researchers in the field of anxiety disorders to find new means of exposing patients. It led virtual reality to be used in several outcome studies that have shown that exposure conducted in virtual reality is an effective and empirically validated treatment of specific phobias [15-18].

Actually, more than 40 clinical trials have been conducted so far (for reviews see [15] to [18]). Although some studies correspond more to pilot or uncontrolled clinical trials, there has been many strong and convincing randomized clinical trials showing that exposure conducted in virtual reality is more effective than no treatment or a waiting list, more effective than some alternative treatments, and no less effective than in vivo exposure [17-18].

\section{Exposure with virtual reality}

According to Pratt et al. [19], virtual reality is defined as an application that allows a given user to navigate and interact in real time with a three-dimension and computer-generated 
environment. Conducting exposure in virtual reality allows a therapist to expose a person to fear-provoking stimuli (as with traditional means) in a situation that is computer-generated (see Figure 1 for example of various stimuli).
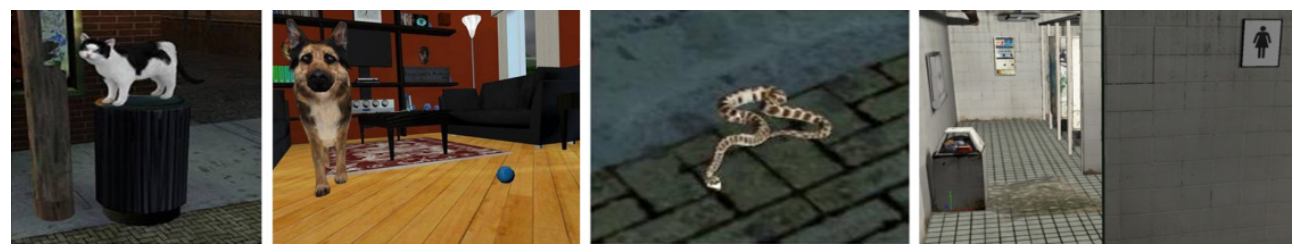

Figure 1. Screenshots of virtual environments used to treat phobia of cat, dogs, snakes and germs.

Many technologies are available to immerse patients in VR, and the currently most popular and affordable one relies on head-mounted-display (HMD) technology, where small monitor screens are mounted in a pair of glasses (see the patient on the left in Figure 2) and paired with a motion tracker, allowing to immersed the patient (usually referred to as the user) in a virtual environment where he or she can be gradually exposed to his or her fear. Semantically, it is important not to describe conducting exposure in virtual reality as "virtual exposure" or "virtual therapy" since it is the stimulus that is virtual, not the exposure, and the therapy is quite real. Instead of using the lengthy and precise expression "exposure conducted in virtual reality", authors are increasingly using the expression "in virtuo", a term coined by Tisseau [20]. In virtuo was created through an analogy with adverbial phrases from Latin such as in vivo (an expression commonly used to describe exposure conducted in real life situations, as opposed to require the patient to imagine the feared stimuli), in vitro (meaning in glass) and in silico (meaning in silicon). When learning to use in virtuo exposure, therapists must become familiar with two concepts, presence and virtual reality induced negative side effects.

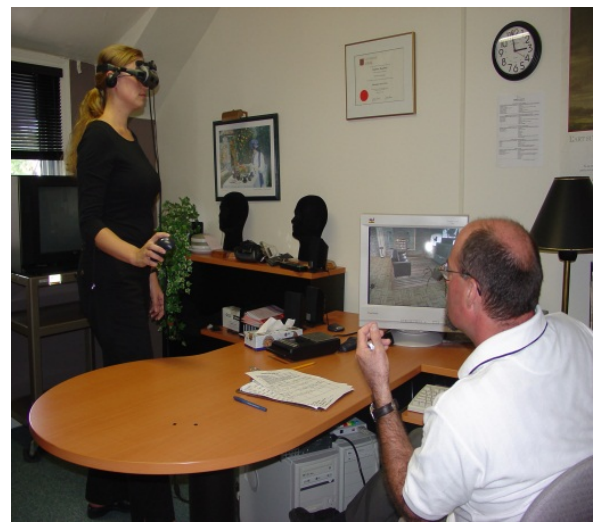

Figure 2. Illustration of an in virtuo exposure session using a HMD.

The notion of presence is considered as very important in virtual reality [16]. Presence is often defined as the perception of "being there" inside the virtual environment in which the 
individual is immersed, even if the person is physically in another environment [21]. Researchers usually agree on this simple definition, although most of them add somewhat different nuances to it [22]. Bouchard et al. [23] proposed a more elaborated view based on the notion of presence resting on a continuum, from a basic but complex and automatic perceptual illusion caused by multisensory integration, up to a sense of meaning and being there in the virtual environment. The gradient on the continuum begins at the most cognitively implicit and automatic level referred to as proto-presence, it evolves into core presence and, at the highest end of the continuum, the perceptual illusion enters a range referred to as extended presence. This terminology was proposed to match Damasio's [24] three neurological layers of consciousness. It builds on propositions by Riva and Waterworth [25-27], although it focuses on defining presence as essentially a strong perceptual illusion leading to a sense of meaning about the events occurring in the virtual environment. The subjective feeling of being "there" therefore refers to presence experienced at the highest end of the continuum and automatic behaviours such avoiding to collide with a virtual wall refers to core presence.

Some conditions seem associated to the development of the feeling of presence and increasing its intensity on the continuum from proto-presence to extended presence. Sadowski and Stanney [22] summarized seven factors contributing to the feeling of presence, and additional empirical evidences were provided by Youngblut [28]. These factors are summarized in Table 1.

The relationship between the feeling of presence and the treatment outcome of in virtuo exposure for phobias is still unclear. However, because developing new internal representations and associations between the feared stimuli and the lack of threat is the well known key ingredient in the process of change underlying exposure for phobias $[4,8,12]$, it is unlikely that presence in itself could be an essential mediator of treatment outcome. Why would feeling more or less present in the virtual environment cure phobias? It is more likely that feeling present allows, at least to some extent, the virtual stimuli to elicit anxiety, exposure to occur, and traditional treatment mechanisms to take place. The feeling of presence during in virtuo exposure may therefore be more directly related to the anxiety reaction triggered by the virtual stimuli, play the role of a moderator of treatment outcome, and involve in a bidirectional relationship where presence influences anxiety and vice-versa.

Clinical experience suggests that the relationship between anxiety and presence is probably not linear. First, people who are predisposed to relate emotionally to the virtual stimuli, such as phobics in the case of phobogenic stimuli, react with stronger emotions and report more core and extended presence than "normal controls" [29-30]. Second, clinicians and experimenters often mention that users who do not feel present at all do not feel anxious when exposed to anxiety provoking stimuli. Third, there seems to be an unknown trigger point where some level of presence is sufficient to lead to a strong sense of anxiety and more presence contribute only moderately to further increase in anxiety, as illustrated in Figure 3. These clinical observations need to be substantiated by empirical evidences, but in the meantime they may guide therapists in understanding why a minimal amount of presence 


\begin{tabular}{|c|c|c|}
\hline & Description & Explanation \\
\hline $\begin{array}{l}\text { System- } \\
\text { related } \\
\text { factors }\end{array}$ & $\begin{array}{l}\text { The immersion should foster interactions and } \\
\text { replicate well the physical reality by stimulating } \\
\text { the senses as it would be the case in the physical } \\
\text { reality and help forgetting the interface between } \\
\text { the user and the system. Examples include } \\
\text { tracking head movements, offering a larger field } \\
\text { of view, stimulating multiple senses, using } \\
\text { stereoscopic displays, providing multimodal } \\
\text { interactions and using ergonomically good } \\
\text { sensors and effectors. }\end{array}$ & $\begin{array}{l}\text { A poorly designed system might cause } \\
\text { a degradation of the immersive } \\
\text { experience. The immersion does not } \\
\text { require perfect realism, but the VE } \\
\text { itself must be well developed to allow } \\
\text { natural multisensory integration that is } \\
\text { credible and is meaningfully } \\
\text { interpreted within the perceived } \\
\text { internal state of the user. }\end{array}$ \\
\hline $\begin{array}{c}\text { Ease of } \\
\text { interaction }\end{array}$ & $\begin{array}{l}\text { The immersion offers seamless interactions that } \\
\text { allow the user to be oriented in, to navigate in } \\
\text { and to interact with the } \mathrm{VE}^{*} \text {. }\end{array}$ & $\begin{array}{l}\text { Unrealistic or asynchronous } \\
\text { interactions might prevent a } \\
\text { meaningful integration of information } \\
\text { coming from the various senses, } \\
\text { including proprioception, and deviate } \\
\text { attention away from the experience in } \\
\text { the VE and towards the interface and } \\
\text { the synthetic nature of the experience. }\end{array}$ \\
\hline $\begin{array}{l}\text { User- } \\
\text { initiated } \\
\text { control }\end{array}$ & $\begin{array}{l}\text { The immersion allows an immediate response, } \\
\text { the correspondence of the patient's actions and } \\
\text { the natural aspect of the control mode. }\end{array}$ & $\begin{array}{l}\text { An implicit sense of agency, or user's } \\
\text { natural impression that he or she is the } \\
\text { cause of the actions happening in the } \\
\text { VE is important, and therefore controls } \\
\text { should be seamless and concordant } \\
\text { between the user's actions and the } \\
\text { effectors reactions. }\end{array}$ \\
\hline $\begin{array}{l}\text { Objective } \\
\text { realism }\end{array}$ & $\begin{array}{l}\text { The stimuli allow continuity, consistency, } \\
\text { connectedness and meaningfulness of the } \\
\text { presented stimuli. The stimuli can be visual, } \\
\text { auditory, olfactory, etc. }\end{array}$ & $\begin{array}{l}\text { Poorly designed or replicated stimuli } \\
\text { may impair how stimuli are detected, } \\
\text { appraised, interpreted as well as the } \\
\text { meaning emerging from the immersive } \\
\text { experience. Objective realism must be } \\
\text { interpreted in the global context of the } \\
\text { immersion instead of essentially based } \\
\text { on how perfectly each stimulus is } \\
\text { replicated. }\end{array}$ \\
\hline $\begin{array}{l}\text { Social } \\
\text { factors }\end{array}$ & $\begin{array}{l}\text { The immersion should provide opportunities to } \\
\text { interact and communicate with virtual humans, } \\
\text { or other users involved in the immersion, and } \\
\text { allows the virtual humans, or other users, to } \\
\text { acknowledge the user's existence in the VE. }\end{array}$ & $\begin{array}{l}\text { If the virtual humans or avatars of } \\
\text { other users in the VE do not } \\
\text { acknowledge the existence of the user, } \\
\text { it can impair the perception that the } \\
\text { patient « exists » in the VE. }\end{array}$ \\
\hline $\begin{array}{l}\text { Duration of } \\
\text { immersion }\end{array}$ & $\begin{array}{l}\text { The immersion should provide sufficient time } \\
\text { allows the user to be familiarized with the task } \\
\text { and the VE, as well as for sensory adaptation. }\end{array}$ & $\begin{array}{l}\text { Avoids unnecessarily prolonged } \\
\text { immersion that could be associated } \\
\text { with unwanted negative side effects } \\
\text { induced by the immersion. }\end{array}$ \\
\hline $\begin{array}{l}\text { Internal } \\
\text { factors }\end{array}$ & $\begin{array}{l}\text { Identifies the individuals' characteristics that } \\
\text { help to increase presence. }\end{array}$ & $\begin{array}{l}\text { Individual differences influencing how } \\
\text { a user will process the information } \\
\text { afforded by the immersion. }\end{array}$ \\
\hline
\end{tabular}

*VE $=$ Virtual environment

Table 1. Seven factors influencing the feeling of presence, adapted from Sadowski and Stanney [22]. 
is required, and why the treatment is not more effective when delivered with immersions in very expensive technologies such as immersive rooms (see the illustration of the immersive room in Gatineau in Figure 4) [31,32] or hydrolic platforms [33] than the much more affordable HMD technology.

\section{The relationship between anxiety and presence may not be linear}

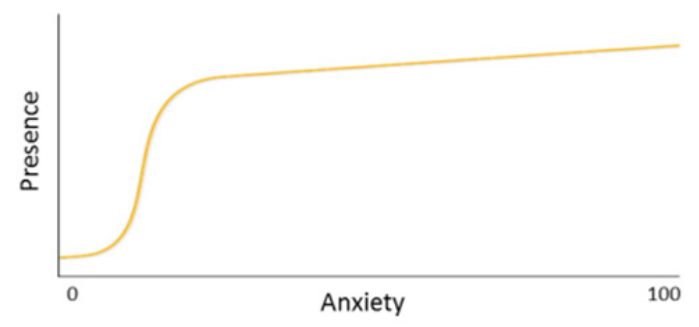

Figure 3. Illustration of the potential relationship between anxiety and presence.

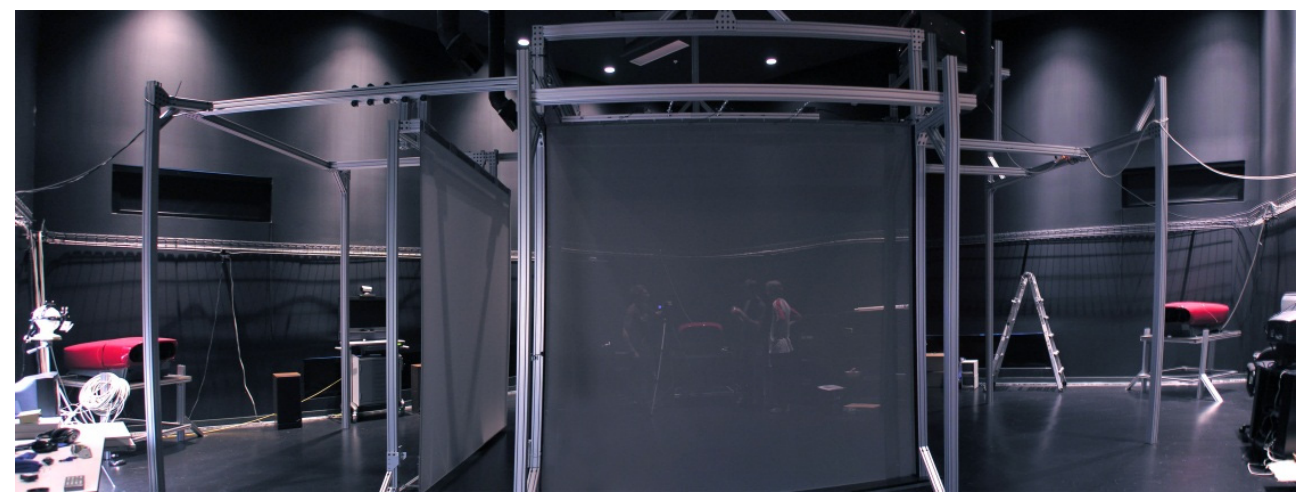

Figure 4. A room-size immersive system where the user stands up in a cube with stereoscopic images retro-projected on its wall to create a very strong sense of presence.

Another important concept to address before describing the treatment manual is the potential negative side effects that can be induced by the immersion in VR. These unwanted side effects are often called "cybersickness" [34], although they do not refer to an actual sickness or illness. The term was coined following the use of common expressions such as sea sickness, motion sickness and simulator sickness. Unwanted side effects are often reported in the literature, but interpreting the data is difficult because the occurrence of unwanted side effects is influenced by several factors, including what the user does during the immersion, the physical fitness of the user and the use of older less powerful technologies. Early studies [35] report that between $50 \%$ to $100 \%$ of users feel some 
dizziness, $20 \%$ to $60 \%$ feel some abdominal symptoms, at least $60 \%$ experience some side effects during their first immersion, and about 5\% feel severe symptoms. Negative unwanted side effects are routinely measured using a well established instrument, the Simulator Sickness Questionnaire (SSQ) [36]. More recent report confirmed some of these incidence rates. For example, Sharples et al. [37] found increase in SSQ scores postimmersion in almost $70 \%$ of users of HMD or large projection screens technologies, compared to $37 \%$ of users immersed using traditional computer monitors. Two reports [3839] have been published on data gathered with adults immersed in situations similar to in virtuo exposure with phobics. Bouchard et al. [38] examined SSQ scores post in virtuo exposure therapy sessions and found the majority (94\%) of users reported having at least one slight symptom listed on the SSQ. But this observation is hard to interpret since these symptoms might have been present before the immersion or may be symptoms of anxiety. Nevertheless, $20 \%$ of their sample reported high scores on the SSQ, which is consistent with other studies revealing the occurrence of side effects in users. None of the participants in Bouchard et al. [38] had to stop the immersion dues to negative side effects and for $92 \%$ of the users the intensity of symptoms was rated as "slight". Another study in the same article replicated what was found in experimental settings, showing that therapy sessions with in virtuo exposure requiring more movements from the user, such as walking to different locations in the virtual environment, induced more unwanted side effects than immersion requiring only to sit and look around, such as in virtuo exposure for fear of flying. Finally, they [38] followed-up some participants 24 hours post-immersion with the SSQ. Their data indicated that side effects were not an issue after the therapy session. Interestingly, the SSQ scores were higher before than after the immersion, suggesting that apprehension and other factors may inflate SSQ scores. In sum, this publication shows that negative unwanted side effects do occur, should be monitored by therapist, but should not be a source of concern for the vast majority of patients.

Bouchard et al. [39] targeted more specifically the assessment of unwanted side effect of a VR immersion using the SSQ and the potential overlap with anxiety symptoms. First, results of their factorial analysis conducted with more than 500 users questioned the scoring method of the SSQ and led to propose: (a) to systematically report the total score without following the weighting procedure suggested for the SSQ items, and (b) a 2-factor solution consisting of nausea and oculomotor symptoms. In another experiment reported in the same paper, scores on the SSQ correlated with a self-report measure of anxiety after participants were subjected to standardized stressor that did not involve any immersion at all. In a third experiment, they found a few items of the SSQ that were more strongly associated with anxiety than cybersickness. This study [39] did not provide a definitive answer on the confound between anxiety induced by in virtuo exposure and symptoms of unwanted negative side effects rated on the SSQ. But is raises concern that post-immersion scores on the SSQ may be inflated by anxiety experienced during in virtuo exposure. Together, the studies by Bouchard's team also show the importance of administering the SSQ before the immersion, as participant's apprehension toward both the immersion and exposure may artificially inflate scores on the SSQ, and of interpreting the scores with caution. 
To understand the causes of the unwanted negative side effects, it is possible to analyse two global types of factors: those related to the hardware itself, and those related to interacting with the virtual environment. Wearing a HMD that is too heavy, bulky or too tightly strapped around the head may induce some neck strain and headache. Holding a heavy computer mouse or other interface in one had for a long time could also be unpleasant during long in virtuo exposure sessions, especially with children. These problems are becoming less of a problem as technology improves and therapists are paying attention to the user's comfort during the immersion. Tension in ocular muscles could also occur during lengthy immersions. Just as watching television from a very short distance or focusing on the computer monitor while working for a long period of time create eye-strain, keeping the eyes in a fixed position to look at tiny images displayed from a few centimetres away can induce ocular discomfort. Using stereoscopy without correction for interpupillary distance is also a potential source of negative side effects. A simple solution to reduce these problems is available for therapists and based on simple ergonomic principles: limit the duration of immersions to allow the eyes focusing at a different point than the displays in the HMD. The rule of thumb is to take a pause in the immersion after about 20 minutes or so. It can be a nice occasion for the therapist to discuss what happened during the in virtuo exposure, before continuing the immersion if time allows it. The duration of the immersion should also be gauged based on what is happening in the exposure session in order not to interrupt the psychotherapeutic change process.

A second set of factors inducing unwanted negative side effects relates to motion, user's behaviour and the task required by the therapist. In the physical reality and under normal conditions, physical movements are perceived by the visual, vestibular and proprioceptive systems and all converging information from theses senses should be consistent and match with each other. In addition to using visual cues, postural imbalance is assessed and maintained by the organism based on the head's orientation as detected by the vestibular system and by proprioception. While immersed in VR, quite as much as in other situations inducing motion sickness, a mismatch between these senses can occur. For example, a mismatch between the visual and vestibular system can occur if the motion tracking system is not fast enough to accurately track head rotations, if the computer is not powerful enough to update and send to the HMD a matching version of the virtual environment, or if the content of the virtual environment was not optimized when it was created and requires too much computing power. A lag between actual motion and delivering its corresponding effect to the user might induce nausea and disorientation. A mismatch with the proprioceptive system can also contribute to some symptoms, probably to a lesser extent. Other effects could also induce cybersickness, such as vection and rotations or movements perceived in the peripheral areas of the visual field $[35,37,40]$. The simplest explanation for the occurrence of nausea symptoms induced by immersion is referred to as the sensory conflict theory [41] and, as suggested by Treisman [42] and Money [43] based on an evolutionary perspective, could be a reaction from the organism to get rid of potential poisonous or intoxicating substances. These explanations are not without criticisms (see [44]) and a lengthy description of this topic would digress for the objective of the current chapter. Lawson et al. [35] added the possibility that some side 
effects might also be linked to the Sopite Syndrome, which is an excessive drowsiness, difficulty concentrating and apathy induced by motion.

Based on factor analyses of symptoms experienced mostly in military training simulators, Kennedy et al. [36] proposed to organize the temporary unwanted negative side effects found in VR in three groups: (1) ocular (e.g., blurred vision, headache), (2) disorientation (e.g., vertigo, dizziness) and (3) nausea (e.g., nausea, vomiting). Following factor analyses of symptoms after immersion of users recruited from the general population or among people diagnosed with anxiety disorders [39, 45], the best factor structure of the SSQ in these samples appears to be two factors describing nausea and oculomotor symptoms. The list of symptoms measured by the SSQ is reported on Table 2 and organized according to the factor structure found in a sample of adults suffering from anxiety and phobic disorders.

\begin{tabular}{|c|c|}
\hline Nausea symptoms & Oculomotor symptoms \\
\hline $\begin{array}{ll}\text { - } & \text { General discomfort } \\
\text { - } & \text { Increased salivation } \\
\text { - } & \text { Sweating } \\
\text { - } & \text { Nausea } \\
\text { - } & \text { Dizzy (eyes open) } \\
\text { - } & \text { Vertigo } \\
\text { - } & \text { Stomach awareness } \\
\text { - } & \text { Burping }\end{array}$ & $\begin{array}{ll}\text { - } & \text { Fatigue } \\
\text { - } & \text { Eyeadache } \\
\text { - } & \text { Difficulty focusing } \\
\text { - } & \text { Difficulty } \\
\text { - } & \text { Fullnentrating } \\
\text { - } & \text { Blurred vision }\end{array}$ \\
\hline
\end{tabular}

Table 2. Nausea and oculomotor symptoms of the SSQ in anxious patients [39]

What the therapists ask users to do during the immersion may also affect the induction of side effects. For example, asking users to rotate frequently on themselves during an in virtuo exposure session may easily lead to disorientation and nausea. On the opposite, guiding users to move at a normal or slower pace would limit the occurrence of unwanted side effects. Other factors fall under the control of the therapist. For example, a few researchers found that some users report a linear increase in symptoms during long immersions [46]. Kennedy et al. [46] also reported habituation and a decrease in side effects with repeated immersions. As a rule of thumb, it is suggest that if there is no reason to stop the immersion prematurely, the unwanted negative side effects should be within acceptable levels for immersions lasting between 10 to 60 minutes. Other user's characteristics that may need to be taken into account are suffering from migraine headache [47], being prone to motion sickness [60] and age. Stanney et al. [40] suggested that susceptibility is greater in children aged between two and twelve years old, although this was not supported in a least one sample of children [47]. In order to reduce the incidence and intensity of unwanted negative side effects induce by immersions, clinicians can take some basic precautions (see [37,40] for a more detailed list). Following the preventive strategies listed in Table 3 contributes to reduce patients discomfort while conducting in virtuo exposure, at least based on past experience in experimental and clinical research centers. 
List of useful strategies therapists should consider using with their patients

- Inform users about cybersickness before the first immersion.

- Inform users about behaviours that can exacerbate side effects.

- Allow users to control their movements in the virtual environment.

- Monitor the user to detect unwanted side effects, provide reassurance and do not confound cybersickness and signs of anxiety. Look for red flags, such as excessive sweating, postural imbalance, burping, restricted movements for a significant duration, nausea.

- Assess symptoms with the SSQ if necessary, and administer the instrument before and after the immersion.

- Terminate the immersion if side effects are disturbing.

- Use adequate hardware and software.

- Limit the duration of the immersion.

- Exclude users who are highly susceptible to motion sickness, or have conditions that would preclude the use of VR, or otherwise conduct the immersion with caution.

- Assess the presence of side effects after the therapy session.

- Do not let the user leave the clinic unless there is no side effect. Waiting 15 minutes post-immersion before allowing the user to leave is a routine procedure in our clinics and lab.

Table 3. Simple preventive strategies to control "cybersickness"

\section{The program's philosophy, objectives and procedures}

The program developed at the Université du Québec en Outaouais to treat specific phobias in older children, adolescents and adults has been used with success at the university clinic, at the Pierre-Janet Hospital, in other research centers and in private practice [15,49-51]. It was designed for people receiving a primary diagnosis of specific phobia [1]. It was not indented to be used without significant modifications for people suffering from a primary disorder that is not specific phobia (e.g., other more complex anxiety disorders, depression, pathological gambling), for people suffering from a phobia accompanied with a more severe comorbid disorder that is more urgent to address, and for people under the effect psychotropic substances that can alter consciousness during the immersion (e.g., alcohol, drugs) or suffering from conditions that may significantly increased the incidence of unwanted negative side effects (e.g., Ménière disease). We strongly discourage people suffering from a specific phobia to use virtual environments and apply this program by themselves without the use of a professional trained in cognitive-behaviour therapy. Virtual environments do not treat phobias; they only represent a tool that is used in the context of a more elaborated treatment. The program has been created to be applied by professionals who have received training in mental health and in the CBT of anxiety disorders. In addition, as exposure in a virtual environment and its associated equipment add a small layer of complexity, it is also suggested that professionals who are interested in this type of intervention familiarise themselves with the VR equipment, learn how to use the available environment and remain aware of the probability of side effects. The program was prepared 
in such a way it can be used with a variety of virtual environments and is therefore not written as a user's guide to any specific software.

This program is based on cognitive-behavioural therapy (CBT). Literature shows that CBT is an efficient treatment mode for anxiety disorders. The goal of the program is to eliminate the symptoms of anxiety in phobic individual through exposure to fear-provoking stimuli in a virtual environment. The program was developed for the clinical trials cited above, where it was administered over five to seven weekly 60-minute sessions, and has been slightly modified since then. When not used in a standardized research protocol, the number of sessions should be tailored to the specific need of each patient. The distribution of sessions' frequency and contents is thus left to the discretion of each therapist. The exposure's pace and phobia severity must also be taken in consideration after a thorough assessment and case conceptualization $[3,4,6,8,12,14]$. In research trials, using homework exposure between therapy sessions was restricted to circumscribe the potentially active therapeutic ingredients. Such restriction is not required in standard clinical practice. Recent developments in the use of portable VR systems, for example based on iPad and iPhone technologies, are currently being tested and will soon allow patients to bring virtual environments at home to complete more in virtuo exercices. Affordable haptic solutions are also being implemented to allow patients perform behaviours where the sense of touch is relevant in the treatment, such as crushing and killing a spider (see Figure 5).
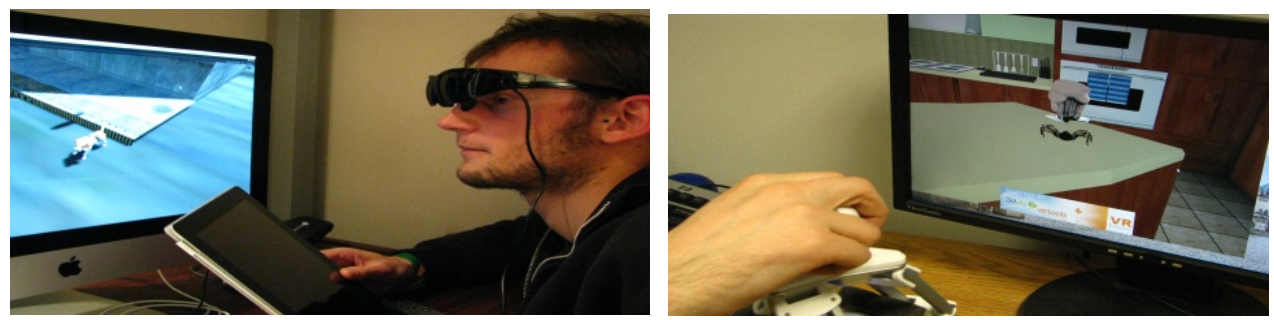

Figure 5. A user immersed in an environment for dog phobia using an iPad (left) and a haptic device allowing crushing and killing virtual spiders during the immersion (right).

Overall, the program is structured around a first introductory session, a few core sessions devoted essentially to in virtuo exposure, and the addition of a relapse prevention module to the last session.

\subsection{First session}

Goals for Session 1:

- $\quad$ Describe CBT principles that will guide the treatment;

- Establish a behavioural contract and the structure of the sessions;

- Present a models of factors maintaining anxiety and specific phobias;

- Warn against the trap of avoidance;

- Identify anxiety-provoking thoughts; 
- Familiarize the patient with the VR system and demystify unwanted negative side effects of immersions;

- Brief cognitive restructuring;

- Establish a hierarchy for the exposure;

- First immersion in VR using a neutral environment that is devoid of the phobic stimuli.

The therapist begins Session 1 by introducing himself briefly. The general clinical picture and patient's problem are assessed to perform a nuanced diagnosis. The information gathered should allow for a good and individualized case formulation (also referred to as functional analysis or case conceptualisation $[4,6,8,13,14])$.

The therapist explains some of the CBT principles to the patient, such as:

- It is based on a model that puts an individual's thoughts, emotions and behaviours in interaction;

- The patient will develop new skills through an active collaboration with the therapist to achieve autonomy in facing his or her own difficulties and feel empowerment;

- The therapist will use the Socratic method to help the patient become aware of his thoughts and actions;

- $\quad$ CBT is brief, structured and focused on current maintaining factors and how one can solve current problems.

It is possible that the expected number of sessions scheduled for the treatment might not be sufficient to completely eradicate the phobia. But efforts must be invested to mobilize the patient to change within the expected time frame, knowing that some adjustment may ultimately be possible. The patient will have to do exposure exercises at home and in "natural" situations in order to maintain the treatment gains. CBT is therefore an emotionally challenging endeavour requiring motivation and efforts.

The therapist explains that CBT, when applied to specific phobias, can is divided in three stages:

- $\quad$ Case formulation and overview of key concepts (first session);

- $\quad$ Exposure (sessions 2 to 6);

- Relapse prevention (session 7).

Following the presentation of this information, the therapist must ask the patients to rephrase in their own words what they understand is required in terms of implication, homework, and the time that will have to be devoted to therapy. Progress will heavily rely on these factors. The therapist has to answers questions (if any) and must agree with the patient on a therapeutic contract that could include, among other things, the number of sessions, their length and a schedule that is convenient to both.

The therapist will provide a model of anxiety, emotions and specific phobias that allows patient to understand what are the maintaining factors involved in the problem and which dysfunctional factors must be target in the treatment. This preliminary step is essential to foster treatment adherence. The following paragraph is an example of the information that 
could be transmitted to the patient. It is important to point out that therapists must not recite this information automatically but rather understand it and explain it with their own style. Concrete examples and metaphors are useful tools to consider.

Example of information to provide about anxiety in general

"Anxiety is an unpleasant emotion triggered by the perception of a threat. Anxiety is also described as an alarm reaction produced by our body in order to protect us against danger. This emotional state affects both the body and the mind. When we are anxious, several physical symptoms manifest themselves such as, for example, muscular tension, perspiration, sweaty palms, faster heart rate. On a psychological level, anxiety is characterized by a state of tension, worry and apprehension. Anxiety is a normal and healthy reaction: it allows our body to be ready to react quickly in front of a potential danger (for example, avoiding, by running, to be hit by a car when we cross the street). However, it becomes a problem when it is triggered when no real danger is present. Indeed, the sensations that we feel when anxious or having a panic attack quickly are unpleasant. When anxiety interferes with our daily life (for example, a person who moves to another country because his snake phobia is too strong), it becomes necessary to learn how to change this automatic association with perceived threat. I sometimes hear people suffering from phobias saying they would have die from a "heart attack» if they had not fled from a specific situation or circumstance. Actually, anxiety generally follows a curve like in this Figure 6 if you do not run away flee from the source of your fear. It will progressively go down after a while. Let's discuss this for a while. What do you think about this? Do you have examples from your own experience that we can examine?"

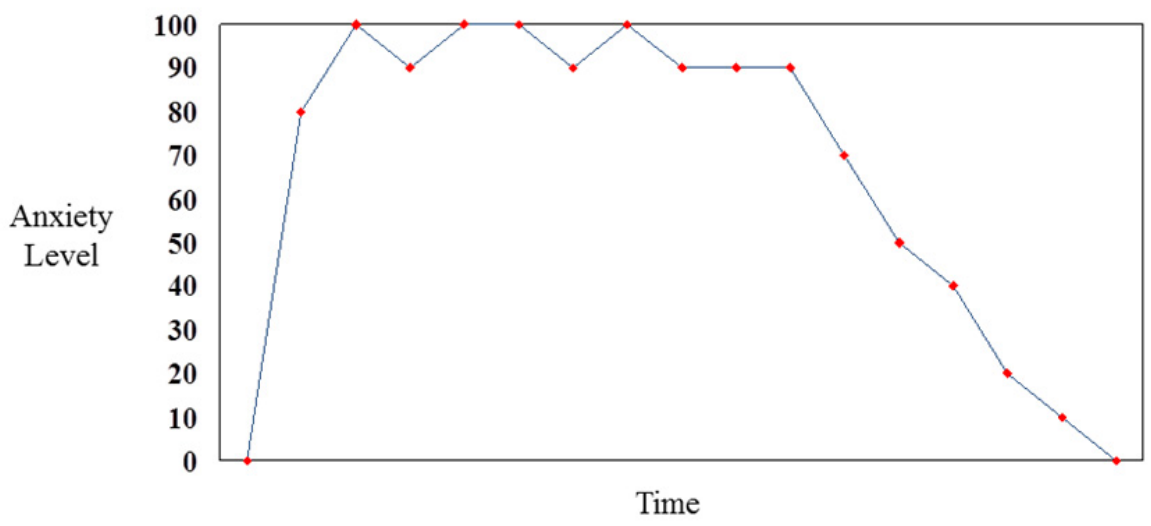

Figure 6. What happens to anxiety over time when there is no avoidance.

After discussing with the patient that anxiety is a normal reaction and it becomes a problem when it interferes with normal functioning, you can introduce the concept of avoidance. "When a person suffering from a phobia sees what she is afraid of, a snake for example, her anxiety will rise rapidly, sometimes up to $90 \%$ or $100 \%$. Who would blame that person to 
avoid the situation? It is normal not wanting to be confronted with that situation and prevent the feared consequences to occur. But can you see how this avoidance could lead to a trap? Can you tell me how avoidance can prevent learning, and feeling with confidence, the disconfirming evidences about the real consequences of facing this stimuli. What about your impressions on the likelihood that such catastrophic consequence will happen? And what about your confidence that you can actually cope with the situation?" Is it possible that if you don't engage in avoidance, anxiety will cease to increase, and remain stable and later decline? Let's take an example from your own situation and examine this."

The four take home messages for the patient are that: (a) avoidance may appear as a logical solution, (b) avoidance maintains perceived threat, (c) stopping avoidance allows gathering disconfirming evidences, and (d) gathering evidence through empirical and emotional experiences allows us to "feel" convinced.

The therapist must also ensure the patient understands the role of appraisal, or the notion it is not the situation that brings the emotion (i.e., anxiety) but rather the interpretation that we make of the situation, how it is perceived. Using an example or the classical metaphor of the branches hitting the window can be more effective to convey this idea than a long lecture. The branches metaphor can be summarized as follow:

"As I was sleeping one night, my partner woke me up in panic saying there is a burglar in the house. I was about to go back to sleep when I heard it myself. Bing, bang, coming from the kitchen. As I was walking to the kitchen, anxious and worrying about all the bad things a burglar can do to us, I shouted that I had called the police, then hold my breath and hid by the kitchen door. As I leaned to see what was happening in the kitchen... I discovered that branches from a tree were blown by the wind and hitting the kitchen's window. There was no burglar, actually it was only branches and the wind ! You (sir / madam), do you think it was ok to feel anxious in that situation?" As the patients contemplate the reasons to be anxious in that situation, make sure he or she can see both sides of the situation: it was natural to be anxious but at the same time there was no danger. Let the patient state that it is because "you didn't know" and then discuss the fact "What you are saying is, it's not as much the events that matter, but how we interpret them".

As a therapist, it is often useful to understand what psychological mechanisms are involved behind perceived threat (or disgust). A heuristic formula made popular by Thorpe and Salkovskis [52] highlights the important target that can be used for cognitive restructuring with anxious patients. It reads as follow:

$$
\text { Perceived threat }=\frac{\text { negative consequences }(\text { or disgust }) X \text { high probabilities } X \text { short imminence }}{\text { Not knowing } \text { what to do }(\text { low perceived self-efficacy })}
$$

When working on dysfunctional beliefs with anxious patients, the therapist can target exaggerated consequences, and / or over estimation of probabilities of occurrence of the feared consequences, and / or the imminence of the feared consequence, and / or the perceived self-efficacy that one can cope with the situation. Considering perceived selfefficacy, or perceived control, on the denominator is quite useful as it can buffer the impact 
of actually negative, realistic and imminent events. It also explains how experience makes people less frightened by some situations. Finally, it guides the therapists in setting the exposure exercises, as in virtuo exposure must disconfirm how negative, likely or imminent the feared consequences are, and how well the patient can cope with the situation [53].

The first 60-minute session is charged with material to learn, which is why the above anxiety equation is rarely explained to the patients and metaphor or examples are regularly used instead of theoretical lectures. The next information that needs to be addressed before beginning exposure is the description of a model of specific phobia. It is more fruitful to describe this model by starting with the patient describing a typical phobic episode and sketching the model on a white board or a piece of paper, than lecturing the patient based on an impersonal and already drawn theoretical model. The therapist could explain the maintaining factors involved in phobias using a simplified model like the one in Figure 7. In order to facilitate patient's understanding, the therapist can use the following information:

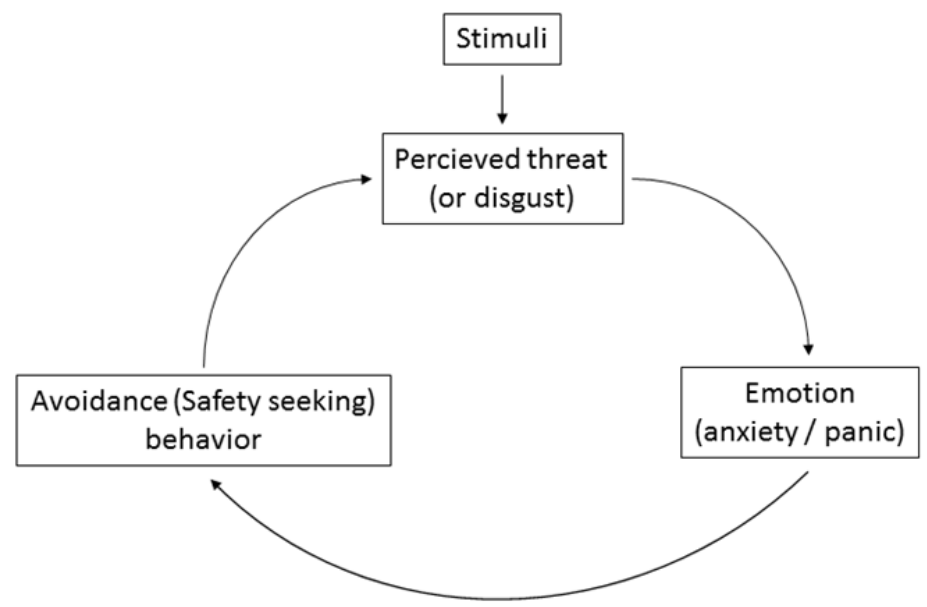

Figure 7. A simplified descriptive model of phobias.

- $\quad$ The triggering or fear-provoking stimuli usually are the phobogenic stimuli themselves (e.g., driving a car, highways, heights, cats), but often times the case formulation will lead to more precise cues (e.g., during take-off in the case of fear of flying, or the claws in the case of a phobia of cats).

- Perceived threat, or disgust, can be acquired in many ways [5], but what matters is not how phobias were acquired but how they are maintained by avoidance.

- At a cognitive level, when the phobic person is confronted with the fear-provoking situation or object, some inner speech occurs. This speech is sometimes so automatic that it may be difficult to notice. In the case of heights phobia, for example, the patient can think that the cliffs are dangerous, if he walks closer to the edge it is sure he will fall and it is sure he will die. The physiological reactions that inevitably follow (trembling, heart pounding, etc.) and the impression that he would not know what to do if the feared situation occurred all confirm that danger is near. 
- The triggering stimuli can take many forms, from the actual feared animal to a cartoonish representation, and avoidance can be as subtle as seeking reassurance from the therapist, positive thinking, or carrying lucky charms.

It is important to have the patient share is or her experience and see how it fits, or not, with the model. Review with examples from the patient how anxiety is maintained by avoidance. Let the patient recall examples illustrating how avoiding situations maintains the dysfunctional beliefs. It is true that avoiding provides a short term relief from anxiety, only until next time he or she is confronted with the stimuli. In addition, a state of general apprehension might remain as the patient is trying to prevent future encounter with the phobogenic stimuli. It is important to work with the patient to detect the avoidance strategies that are used, as it will be essential during exposure to monitor them and progressively get rid of them.

Cognitive restructuring may be used [6], based on the therapist's judgement. In many cases, the patients' either already know their fear is irrational or are extremely well informed. Our experience with the current program is to limit cognitive restructuring to a minimum, mostly because it is not as efficient as exposure. However, an introduction to cognitive restructuring remains in the program because it was found to help patients put in context what they will achieve through exposure, to accept exposure more readily and to provide tools to generalize what they have learned to other areas in their life. It seems easier for the patient to be convinced both logically and « in his guts » about the validity of the alternative functional thoughts if he or she has previously identified and attempted to restructure the dysfunctional beliefs.

The first part of cognitive restructuring is identifying the dysfunctional anxiety-provoking beliefs [6]. For example, the individual can be asked what thoughts are evoked when he is confronted to the phobic stimulus. He can think that if he goes on the plane, there are high chances that it will crash. This is a good example of a dysfunctional belief: even if it is true that such an eventuality could happen, it is important to keep in mind that probabilities are very small (for statistics, see [9]). This new information may not suffice to convince the patient that the fear is irrational, but it can help de-dramatize the situation and, therefore, reduce anxiety levels. Other questions that can help identify dysfunctional anxietyprovoking beliefs: What thought runs in my mind when I am anxious?? What is the worst thing that could happen to me in that situation? What makes this situation more frightening than others? What could make the situation more difficult or easier? What image comes to my mind?

The second part of cognitive restructuring is modifying the dysfunctional beliefs [6]. Following the identification of dysfunctional anxiety-provoking beliefs, the patient learns to become efficient in reframing these thoughts, with the help and support of the therapist. Note that cognitive restructuring is not the equivalent of positive thinking; it is a search for a realistic appraisal based on empirical facts. The role of the therapist is not to argue with the patient, but to collaborate with him in developing alternative and more functional beliefs. Here are a few examples of questions that can help the therapist with cognitive restructuring: What proofs do you have for and against these thoughts? Is there another way to see the 
situation (another explanation)? How would someone else see the situation? Are you I fixing yourself irrational or unattainable goals? Are you reasoning with your emotions instead of your logic? Are your overestimating the degree of control over the events? Are you underestimating the things you can do to cope with the problem? Are you "catastrophizing"? Is your judgement based on impressions or facts? To what extent are you thinking in terms of certitude instead of probabilities? "So what if it happens!!!", is the consequence you fear so bad after all? Let's reinstate that this techniques aims to at least build some confidence in alternative interpretations based on more functional beliefs. With specific phobias, it may be difficult for patients to have a strong confidence in the functional beliefs, or they might say they are convinced logically but not emotionally. At that stage, it is time to test the alternative beliefs with behavioural experiments [5] or exposure. When using the treatment protocol in private practice, it has been our experience to reach this point with most patients within the first therapy session or early in the second session.

The therapist must introduce exposure and provide directions and procedures $[4,8,54]$. In short, exposure can be introduced either as a way to build confidence in the alternative functional beliefs, as a tool to overcome fears by progressively facing them, or as a method to teach the emotional part of the brain (the limbic system) that there is no danger. The stimuli or situation that triggers a small or manageable amount of anxiety will be used first, based on what is available in the virtual environment. For fear of flying, it could be at the gate waiting for boarding or seated inside the airplane, for fear of snakes it could be with a garden snake lying still on the grass and for fear of heights it could be on the fourth floor of a virtual building. The therapist must therefore be aware of the different opportunities afforded by the available virtual environments. For example, a VR environment developed for the treatment pathological gambling may include a virtual bar where the patient can be exposed to social interactions with virtual humans, even if the environment was not designed for that purpose.

After informing the patient about exposure, the therapist should also how exposure will proceed. Firstly, the patient is informed that teamwork is an important treatment component and the therapist, like the patient, possesses equal responsibilities in treatment results. Exposure requires hard work and can only be efficient if the patient accepts his or her role in the team. The patient is also invited to provide suggestions on the exposure plan. It favours empowerment, facilitates treatment adherence and contributes to a sound working alliance. Some patients might apprehend to be exposed to extreme levels of anxiety and would not be able to cope mentally or physically. Subtle avoidance strategies should also be eliminated or otherwise tolerated until they can be stopped, such as taking a benzodiazepine pill before the therapy session or rescheduling the session because "today is a bad day".

The last part of the session could allow for a first contact with the virtual reality system so patients could familiarize themselves with VR before beginning exposure on the next session. Cybersickness should be discussed to see if the patient is prone to motion sickness or suffers from condition that would counter indicate the use of virtual reality in the following session. Patients are often curious about virtual reality and fearful apprehension may be reduced by an immersion in a virtual environment that does not contain any cues 
that would be phobogenic to the patient. In research settings, a first immersion is useful to reduce the effect of novelty on the first contact with the virtual phobogenic stimuli. With children, it is essential to assess patient's expectations toward the virtual stimuli [51]. Children are expecting virtual stimuli used for exposure to be larger, scarier and more dangerous than adults do [55], probably in part because they do not know what to expect from therapists and have a more active imagination.

\subsection{Virtual reality exposure sessions (usually Sessions 2 to 6)}

Goals for Sessions devoted to in virtuo exposure:

- Overcoming fears;

- Stopping avoidance behaviours;

- Developing new associations between the stimuli and the absence of threat;

- Decreasing perceived threat;

- Increasing perceived self-efficacy.

The core of the treatment protocol is exposing the patient to fear-provoking situations in a controlled virtual environment. It is important to underline the difference between therapeutic exposure and ordinary day to day confrontations with the feared stimuli. In therapy, exposure is planned, gradual, controlled and set-up to minimize avoidance, whereas in naturally occurring situations the events are unplanned, far from gradual, uncontrolled and faced with various forms of avoidance, safety seeking behaviours and neutralizations.

Elaboration of the exposure hierarchy is an important step and must be performed with the goals of disconfirming the dysfunctional mental associations and building confidence in new associations with the lack of threat. Therefore, the hierarchy does not have to be linear, evenly paced or with items systematically set on every step of the scale. What matters is to be able to adjust the difficulty level so the patient can successfully engage in emotionally charged situations that will modify the dysfunctional mental representations of the phobic stimuli. The rationale for a progressive hierarchy is to ensure that patients are: (a) not exposing themselves to feared situations that are too great for what they can cope with, (b) building self-efficacy, (c) not engaging in disruptive avoidance behaviours, (e) conclude the exposure with success, and (f) do not set-up for a pace that is too slow. Alternative can be implemented $[3,4,8,12,13,16]$, such as flooding, guided mastery, combining biofeedback, or using antiphobic behaviours to challenge the notion that one must be careful in phobic situations (e.g., jumping off the virtual cliff to show how much control patients have over their actions).

Before initiating the actual exposure session, the therapist should have assessed the patient's understanding of the treatment rationale and the role of avoidance. At this stage, misconception should have been addressed. Although the therapist should begin exposure rapidly in the session to prevent increases in apprehension, the patient should be instructed to focus on what is happening right now in the virtual environment, instead of distracting himself or herself from the feared stimuli. 
When the patient is ready, the patient can put on the HMD and begin exposure in virtual reality, starting with the first element in the pre-established hierarchy. The duration of the immersion should be planned to last between 20 to 30 minutes in order to reduce unwanted negative side effects. However, many immersions can be cumulated in a session if they are spaced by small pauses. Between each immersion, the therapist can discuss what happened during exposure. Since the duration recommended for the immersion is based on a very conservative approach to prevent eyestrain and cybersickness, the therapist should not rely solely and rigidly on the proposed time frame and gauged when it is appropriate to stop based on the psychotherapeutic processes occurring in the session (e.g., it may not be appropriate to stop if anxiety is at its peak value).

Cognitive restructuring, breathing retraining, relaxation and any other strategy that can become reassuring or a distracter must be eliminated during exposure [3,4,8,12,54]. During the immersion, the therapist interactions with the patient have to stay minimal and limited to: (a) asking for verbal ratings (from 1 to 100\%) of anxiety, presence and cybersickness, (b) checking and removing avoidance behaviours, (c) guiding the patient to the next step in the hierarchy, and (d) providing a narrative or instructions that could increase presence (e.g., "Look at that spider, it is so tiny and quick it can probably climb on you hairs) or increase the value of the corrective experience (e.g., "Pay attention to how many people are actually laughing at you during your conference"). Therapists should not hesitate to be creative and use any cue in the virtual environment that can trigger more anxiety during exposure. Exploiting patient's fearful imagination is a very strong asset of in virtuo exposure. For example, in a virtual environment designed for claustrophobia where it is possible to lock the user in a wooden closet and a room with brick walls, a patient once said being immersed in the room in brick walls was much more frightening because it would be impossible to break the door. Since the objective way out was the same in both rooms - removing the HMD to stop the immersion - the therapist noticed the strong sense of presence during that session and later suggested he had lost the key to unlock the brick door and must leave the patient in the room for a few more minutes. It allowed exposing the patient to a much higher step on the hierarchy with exactly the same stimuli.

To foster presence during the immersion, it is important that the therapist attempts to maximize the feeling of presence by helping the patient feel as if the synthetic environment is real. For example, the therapist can prepare the immersion with a narrative providing a context for the exposure (e.g., "We will be leaving Ottawa by plane for a trip to Montreal. Our flight has been delayed for unknown reasons, but I guess since it is raining outside it may be due to poor weather conditions").Guiding the patient in the virtual environment should be done in ways that suggest the experience is real and not computer generated (e.g., ask the patient "Can you walk closer to the spider" and not "Can you push the mouse button to move closer to the virtual spider", or ask "Please turn off the engine before you exit the car" even if it is pointless in a virtual car). During the immersion, it is useful to observe the patient for signs of avoidance (e.g., always looking in a specific direction) and look for cues in the interaction between the patient and the environment to improve the exposure session (e.g., a patient may be invited to turn her back from a bed under which a spider just disappeared and wait until it returns). 
When a patient accomplishes an exposure task in a rigid or unnatural way, the therapist should provide suggestions and guidance in order to improve the quality of his performance (e.g., talking in front of an audience, petting a dog) and eliminate safety seeking behaviour (e.g., always looking through the airplane window). Intermediate objective are sometimes needed. It is a technique that consists in asking during a difficult exposure session to concentrate efforts in reaching an intermediate objective if the planned objective turns out to be too difficult. For example, if a patient suffering from heights phobia cannot walk closer than a few feet away from the edge of a cliff, the therapist could suggest beginning by approaching the edge of the cliff from a different path where a railing is preventing him to fall.

Ideally, exposure should last until anxiety comes back to an acceptable baseline level (for example $20 \%$ ) or the alternative functional belief is sufficiently strong to counter the association with perceived threat. The patient should remain in the exposure situation a few more minutes to make sure anxiety is gone and safety is well established. Exposure must be repeated to generalize across contexts and across therapy sessions. Afterwards, the patient can progress to situations that trigger more anxiety, either by visiting a new virtual environment or by confronting the fear-provoking stimuli more intensely. The therapist must assist the patient during this progression while again paying close attention to potential avoidance behaviours.

Reviewing post-immersion what happened during the exposure exercise is essential. Now it is time to apply other CBT strategies such as cognitive restructuring without risking distracting the patient or facilitating avoidance. Post processing of the emotional experience occurring during exposure serves several purposes. It allows the therapist to: (a) make sure the patient did not engage in avoidance strategies, (b) confirm if the exercise's was set at an adequate level of difficulty and implement corrections if required, (c) help the patient process the emotions that were experiences and the conclusions that should be reached, and (d) plan the next step to be conducted in therapy or as homework. After the session, the patient should remain in the waiting room for a while to make sure no there is no lasting unwanted side effects. It is an ideal moment to administer questionnaires, if needed.

\subsection{Final ession for exposure, relapse prevention and closure (usually Session 7)}

Goals for the final Session:

- Making final touch-up through exposure, if needed;

- Planning further exposure at home, if needed;

- Fostering patient's appropriation of treatment successes;

- Implementing relapse prevention strategies.

There is usually enough time in the last therapy session to conduct some in virtuo exposure if the therapist needs to tie some loose ends and push to reach the top of the exposure hierarchy. The therapist should allocated the last 15 to 20 minutes of this final session to review the progress, boost empowerment and appropriation of treatment success, plan 
homework or further in vivo exposure if needed, detect high risk situations, discuss the eventuality of a relapse, and set-up a relapse prevention plan [24]. The therapist should reinforce the patient's perceived self-efficacy, both toward facing phobogenic stimuli and using a difficult emotion regulation technique. Patient should be able to trust their abilities to detect avoidance strategies, implement an exposure plan and deal with fear. All they need now is time to strengthen and generalize their gains.

As with in vivo exposure, the therapist must now encourage patients to keep exposing themselves to stimuli that were feared before the treatment. Some patients may have not reached their objectives entirely. Any improvement during therapy must first be highlighted. The next exposure steps should be written down, taking into account roadblocks that might have occurred during the treatment. For those who are free from their phobia, creating opportunities to consolidate their newly acquired set of mental representations is important. For example, a patient treated for flying phobia should schedule a flight in the near future, and keep flying once in a while afterwards. It does not mean the treatment is incomplete. But safety seeking behaviours might have been over learned and avoiding contacts with the feared stimuli was one of these behaviours. For example, a patient treated for spider phobia must make a habit of taking the lead in getting rid of spiders when one is found in the family home.

At the final therapy session, it is important to address relapse. Just like an insurance policy that people pay with the hope of never having to claim it, relapse must be discussed in order to prevent a lapse to become a relapse. The program focuses on three ingredients of relapse prevention: (a) patients must be aware that experiencing anxiety is normal and does not mean the occurrence of a relapse, (b) managing well the emotional reaction triggered by a lapse significantly reduces the risk of a relapse, and (c) patients must prepare a cognitivebehavioural plan to deal with lapse and relapse. It must be clear for patients that feeling anxious under certain circumstances is normal. In the case of a lapse, or the reoccurrence of phobic fear, it is unproductive to react in a catastrophic manner, as if everything accomplished in therapy was useless and lost. As with any problem, it is more fruitful to interpret the situation as an opportunity to find out was went wrong and correct it. Actually, the intensity of the guilt and perceived loss of control that a patient feels when phobic fear is returning are associated with the crystallisation of a momentary lapse into a relapse of the phobic disorder. The best attitude is to identify what did not work out, look at what was learned during therapy and make the necessary corrections. The therapist can give the example of falling from a bicycle to illustrate this principle: "I will tell you a story about something that happened to me a few years ago in the Spring. I was going down a hill and had to stop. As I braked forcefully using both the front and back brakes, I was thrown off balance and fell on the street. As I stood up, I was very angry and I lost control for a few moments and give several kicks to the bicycle. Do you think it was a good idea to lose control, feel bad and kick my bicycle? As the patient is telling you that these emotions and behaviour were unproductive, you can add "What you are saying is I must consider my fall as an accident or a glitch; falling down from my bicycle does not mean that I don't know how to ride one, but rather that I should be more vigilant in the future and use more the back brake and less the front brake. A glitch is a source of information, 
not a matter for overacting. So, let's apply what we discussed about my fall from the bicycle to a potential return of phobic fear in your life. You must not blame yourself for what happened, overreact and lose control. Instead, you must look at the way the incident happened and analyse it: have you been taken by surprise? If yes, it is understandable that you have reacted the way you did. Have you been avoiding? A good way to get rid of the problem is to assess the situation, recall what worked for you in therapy and do a few exposure exercises on your own."

As a practical relapse prevention exercise, the therapist should ask the patient to write a letter to himself or herself. The letter must include three sections: (a) information about the differences between a lapse and a relapse, factors and situations at risk for a relapse, and that over reacting aggressively, with guilt and a feeling of losing control is not fruitful; (b) a summary of what was learned in therapy and recommendations the patient would like to formulate; and (c) a list of specific actions and homework to do in order to get rid of the phobia, including suggestions for exposure. Once written, the Letter to Myself is to be sealed and kept by the patient at home with his or her personal documents. In the case of a lapse, or if the patient calls a few years post-therapy, the first thing to do for the patient is to read the letter and engage in the recommended homework.

\section{Conclusion}

The program described in this chapter builds on decades of experimental and clinical research on exposure and CBT for specific phobias [4-8, 11-14]. Conducting exposure with an immersion in virtual reality is not much different than traditional CBT, except for the importance of the feeling of presence and monitoring cybersickness. The key ingredients for an effective in virtuo exposure treatment are the same as in vivo exposure, with a dedication to remove avoidance in all its forms. The program was intended to be delivered in seven active sessions, plus a few preliminary sessions for diagnosis and case formulation. The treatment is described without reference to specific software, which should facilitate its use in various settings. Outcome studies and randomized outcome trial have been conducted with success using this protocol [15,49-51] or other quite similar protocols developed for a specific disorder or software (for reviews[15-18]).

CBT being the only empirically validated and effective treatment for specific phobias [10], it is not surprising that VR applications have been developed for CBT. The consequence is that very few researchers have yet tempted to apply VR technologies in the context of other schools of thoughts. A literature search revealed a few papers from the field of psychodynamic therapy or reflections from a psychodynamic perspective. The research of Optale and collaborators [56] addressed the treatment of erectile dysfunction and premature ejaculation in 160 males. In their experiment, the virtual environment depicted different pathways through a forest in order to symbolically bring male patients back to their childhood, adolescence and later teens. The authors suggest the immersion accelerates a psychodynamic process that eludes cognitive defenses and directly stimulates the subconscious. Hence, the obstacles that lead to sexual dysfunction would be brought to light and modified under the therapist's guidance much faster than with conventional 
psychodynamic psychotherapy. Optale reported that positive results were found with his technique. Another approach to refine the understanding of the possibilities of VR in psychodynamic therapy is to use VR within a cognitive-behavioural program but analyse the results from a psychodynamic point of view. In the research of Wiederhold and collaborators [57], a case report of a patient treated with in virtuo exposure for fear of flying is discussed based on psychoanalytic principles. During her treatment, the patient was said to "progressively learned to abandon her defensive dissociation mechanism while in immersion". The authors suggest this was possible because the transference that the patient developed occurred primarily with the virtual environment, rather than with the therapist, so it can serve as a transformational object.

Virtual reality, conceived in a much broader perspective that include everything related to cyberspace, from Internet profiles, video games and television, also stir interest in some psychoanalysts. One of their preoccupations is how new technologies will influence the therapeutic process. At the $46^{\text {th }}$ Congress of the International Psychoanalytical Association, Moreno proposed that by simulating an object, virtual reality may occlude the space between the represented and the representation, thus reducing some frustrations [84]. For instance, children who play video games can now live in the illusion of becoming others. In other words, virtual reality could reduce the difference between fantasy and reality. Similarly, if the representation of an object may subsume the effects of its presentation, the question of the necessity of both parties being physically present for the analysis arises. Thus, according to Moreno, clinicians need to address the difference between the traditional analytic process and the analytic process in treatments of anxiety disorders delivered through e-mail, telephone or Skype ${ }^{\mathrm{TM}}$. With the growing popularity of social networks like Facebook, some psychoanalysts also think there is a need to redefine the traditional views of privacy and anonymity in therapeutic settings [58]. Research about psychodynamic therapy and VR is still limited to just a few papers and creative reflections. Neubeck and Neubeck [59] proposed a hypothetical description of psychodynamic possibilities in VR. For instance, they suggested that VR could be used to create symbolic reproductions, to allow patients to associate with diffusely-built fictitious worlds, and to create pictures that can help them cope with hidden memories. However, these ideas still need to be implemented before we know how VR could complement and support psychodynamic treatment.

Another matter of interest in psychologists from other approaches than CBT, and also among CBT therapists, is the impact of technology on therapeutic alliance. Indeed, little is known about the role of therapeutic alliance in technology-assisted interventions. Therapeutic alliance between the patient and the therapist is often defined as the strength of: (a) the collaborative agreement on the general goals of the treatment, (b) the collaborative agreement on the specific tacks required in the treatment, and (c) the quality of the affective bond between therapist and patient. In 2008, Meyerbröker and Emmelkamp [60] published a study on the role of the therapeutic alliance during in virtuo exposure for fear of flying and acrophobia. Their results indicated that the quality of the therapeutic alliance according to the patient was positively related to anxiety reduction following exposure, but only for the fear of flying participants. The authors suggested that one explanation for the inconsistent 
results between both types of phobias could be the nature of the questionnaire used to measure the therapeutic alliance.

In summary, VR does not have to be used only by CBT therapists. Other therapeutic approaches are starting to explore what can be done with immersions in synthetic environment. In the meantime, real-time interactions with virtual stimuli allow CBT therapist to create emotionally curative experiences that can be used to treat phobias. In the near future, applications will be widely available using augmented reality, portable technologies, or live biofeedback interaction between the user and the virtual environment. But using technology should not become an aim in itself; it remains a tool to assist well trained professionals in the delivery of mental health services.

\section{Author details}

Stéphane Bouchard*, Geneviève Robillard and Claudie Loranger

Université du Québec en Outaouais, Gatineau, Québec, Canada

Serge Larouche

Centre hospitalier Pierre-Janet, Gatineau, Québec, Canada

\section{Acknowledgement}

The preparation of this chapter was made possible thanks to financial support from the Canada Research Chairs and Canadian Foundation for Innovation programs. The authors wish to acknowledge the contribution of Belle Paquin and Sophie Côté to the preparation of an earlier version of the treatment program. All pictures and screenshots, courtesy of the Cyberpsychology Lab of UQO.

\section{References}

[1] American Psychiatric Association (2000) Diagnostic and Statistical Manual of Mental Disorders - Text Revision (4e ed.). Washington: APA. 943 p.

[2] Martin M Antony, Mark A Watling (2006). Overcoming Medical Phobias. Oakland: New Harbinger Publications, Inc. 164 p.

[3] Martin M Antony, Randy E McCabe (2005) Overcoming Animal and Insect Phobias. Oakland (CA): New Harbinger Publications, Inc. 149 p.

[4] Jonathan S Abramowitz, Brett J Deacon, Stephen PH Whiteside (2011). Exposure Therapy for Anxiety: Principles and Practice. New York: The Guilford Press. 398 p.

[5] David H Barlow (2002). Anxiety and its Disorders (2 ${ }^{\text {nd }}$ Ed.). New York: Guilford Press. $704 \mathrm{p}$.

[6] David A Clark, Aaron T Beck (2010). Cognitive Therapy of Anxiety Disorders: Science and Practice. New York: The Guilford Press, 628 p.

\footnotetext{
${ }^{*}$ Corresponding Author
} 
[7] Graham CL Davey (1997) Phobias: A Handbook of Theory, Research and Treatment. Brighton: John Wiley \& Sons. 451 p.

[8] Michael W Otto, Stefan G Hofmann (2011) Avoiding Treatment Failures in the Anxiety Disorders. New York: Springer. 405 p.

[9] Martin M Anthony, Richard P Swinson (2000) Phobic Disorders and Panic in Adults: A Guide to Assessment and Treatment. Washington: APA. 422 p.

[10] Peter E Nathan, Jack M Gorman (2007) A Guide to Treatments that Work (3rd ed.). New York: Oxford.784 p.

[11] Marshall, W.L (1985) Exposure. In: Bellack AS \& Hersen M, editors. Dictionary of Behaviour Therapy Techniques. New York: Pergamon Press. pp.121-124

[12] David CS Richard, Dean L Lauterbach (2007) Handbook of Exposure Treatment. Burlington: Elsevier, inc. 437 p.

[13] William T O'Donohue, Jane E Fisher (2009). General Principles and Empirically Supported Techniques of Cognitive Behaviour Therapy. New Jersey: John Wiley \& Sons, Inc. 743 p.

[14] Jacqueline B Persons (2008) The Case Formulation Approach to Cognitive-Behaviour Therapy. New York: The Guilford Press. 273 p.

[15] Bouchard S, Côté S, Richard DS (2006) Virtual Reality Applications of Exposure. In: Richard DS and Lauterbach D, editors. Handbook of exposure. New York: Academic Press. pp. 347-388.

[16] Brenda K Wiederhold, Mark D Wiederhold (2005) Virtual Reality Therapy for Anxiety Disorders. Advances in Evaluation and Treatment. Washington, DC: American Psychological Association Press.

[17] Côté S, Bouchard S (2008) Virtual Reality Exposure for Phobias: A Critical Review. Journal of CyberTherapy and Rehabilitation. 1(1): 75-91.

[18] Meyerbröker K, Emmelkamp, PMG (2010) Virtual Reality Exposure Therapy in Anxiety Disorders: A Systematic Review of Process and Outcome Studies. Depression and Anxiety. 27(10): 933-944.

[19] Pratt DR, Zyda M, Kelleher K (1995) Virtual reality: In the Mind of the Beholder. IEEE Computer. 28(7): 17-19.

[20] Tisseau J (2008) In Vivo, In Vitro, In Silico, In Virtuo. 1st Workshop on SMA in Biology at Meso or Macroscopic Scales, Paris, July 2, 2008.

[21] Draper JV, Kaber DB, Usher JM (1998) Telepresence. Human Factors. 40(3): 354-375.

[22] Sadowski W, \& Stanney KM (2002) Presence in Virtual Environments. In: Stanney KM, editor. Handbook of virtual environments : Design, implementation and applications. Mahwah : IEA. 791-806.

[23] Bouchard S, Dumoulin S, Monthuy-Blanc J, Labonté-Chartrand G, Robillard G, Renaud P (2011, submitted). Perceived Realism Contributes to the Presence Experienced in a Virtual Environment. Interacting with Computers.

[24] Antonio Damasio (1999) The Feeling of What Happens: Body and. Emotion in the Making of Consciousness. New York: Harcourt Brace. 386 p. 
[25] Riva G, Waterworth JA, Waterworth EL (2004) The Layers of Presence: A Bio-cultural Approach to Understanding Presence in Natural and Mediated Environments. CyberPsychology \& Behaviour. 7(4): 402-416.

[26] Riva G (2009) Is presence a technology issue? Some Insights from Cognitive Sciences. Virtual Reality. 13: 159-169.

[27] Waterworth JA, Waterworth EL, Mantovani F, Riva G (2010) On Feeling (the) Present: an Evolutionary Account of the Sense of Presence in Physical and ElectronicallyMediated Environments. Journal of Consciousness Studies. 17(1-2): 167-188.

[28] Youngblut C (2007) What a Decade of Experiments Reveals About Factors that Influence the Sense of Presence: Latest Findings. Virginia: Institute for Defense Analyses. 214 p.

[29] Robillard G, Bouchard S, Fournier T, Renaud P (2003) Anxiety and Presence During VR Immersion: A Comparative Study of the Reactions of Phobic and Non-Phobic Participants in Therapeutic Virtual Environments Derived from Computer Games. CyberPsychology and Behaviour. 6(5): 467-476.

[30] Loranger C, Bouchard S, Boulanger J, Robillard G. (2011) Validation of Two Virtual Environments for the Prevention and Treatment of Pathological Gambling. Oral presentation at the $16^{\text {th }}$ Annual Cybertherapy \& Cyberpsychology Conference, Gatineau, June 20-22.

[31] Krijn M, Emmelkamp PMG, Biemond R, de Wilde de Ligny C, Schuemie MJ, van der Marst CAPG (2004) Treatment of Acrophobia in Virtual Reality : The Role of Immersion and Presence. Behaviour Research and Therapy. 42: 229-239.

[32] Bullinger A, Angehrn I, Wiederhold BK, Nueller-Spahn F, Mager, R (2005) Treating Acrophobia in a Virtual Environment. In: Wiederhold BK, Riva G, Bullinger MD, editors. Annual Review of CyberTherapy and Telemedecine. San Diego, CA: Interactive Media Institute. pp. 93-100.

[33] Mülhberger A, Herrmann MJ, Wiedemann G, Ellrring H, Pauli P (2001) Repeated Exposure of Flight Phobics to Flights in Virtual Reality. Behaviour Research and Therapy. 39:1033-1050.

[34] McCauley ME, Sharkey TJ (1992) Cybersickness: Perception of Self-Motion in Virtual Environments. Presence. 1(3): 311-318.

[35] Lawson BD, Graeber DA, Mead AM (2002) Signs and Symptoms of Human Syndromes Associated with Synthetic Experience. In: Stanney KM, editor. Handbook of Virtual Environments: Design, Implementation, and Applications. Mahwah: IEA. pp. 589-618.

[36] Kennedy RS, Lane NE, Berbaum KS, Lilienthal MG (1993) Simulator Sickness Questionnaire: An Enhanced Method for Quantifying Simulator Sickness. International Journal of Aviation Psychology. 3: 203-220.

[37] Sharples S, Cobb S, Moody A, Wilson JR (2008) Virtual Reality Induced Symptoms and Effects (VRISE): Comparison of Head Mounted Display (HMD), Desktop and Projection Display Systems. Displays. 29: 58-69.

[38] Bouchard S, St-Jacques J, Renaud P, Wiederhold BK (2009) Side Effects of Immersions in Virtual Reality for People Suffering from Anxiety Disorders. Journal of Cybertherapy and Rehabilitation. 2(2): 127-137. 
[39] Bouchard S, Robillard G, Renaud P, Bernier F (2011) Exploring New Dimensions in the Assessment of Virtual Reality Induced Side-Effects. Journal of Computer and Information Technology. 1(3): 20-32.

[40] Stanney KM, Kennedy RS, \& Kingdon K (2002) Virtual Environment Usage Protocols. In: Stanney KM, editor. Handbook of Virtual Environments: Design, Implementation, and Applications. Mahwah: IEA. pp. 721-730.

[41] James T Reason, J J Brand (1975) Motion Sickness. London: Academic Press.

[42] Treisman M (1977) Motion Sickness: An Evolutionary Hypothesis. Science. 197: 493-495.

[43] Money KE, Lackner J, Cheung R (1996) The Autonomic Nervous System and Motion Sickness. In: Yates BJ, Miller AD, editors. Vestibular Autonomic Regulation. Boca Raton, FL: CRC Press. pp. 147-173,

[44] Stoffregen TA, Riccio GE (1991) An Ecological Critique of the Sensory Conflict Theory of Motion Sickness. Ecological Psychology, 3: 151-194

[45] Bouchard S, Robillard G, Renaud P (2007) Revising the Factor Structure of the Simulator Sickness Questionnaire. Oral presentation at the 12th Annual CyberTherapy Conference 2007, Washington (DC), June 12-14.

[46] Kennedy RS, Stanney KM, Dunlap WP (2000) Duration and Exposure to Virtual Environments: Sickness Curves During and Across Sessions. Presence: Teleoperators and Virtual Environments, 9, 466-475.

[47] Nichols S, Ramsey AD, Cobb S, Neale H, D'Cruz M, Wilson JR (2000) Incidence of Virtual Reality Induced Symptoms and Effects (VRISE) in desktop and projection screen display systems, HSE report 274/2000.

[48] St-Jacques J, Bouchard S (2005) Clinical Applications of Virtual Reality and Cybersickness. In B.K. Wiederhold, G. Riva \& A. H. Bullinger, (Eds). Annual Review of CyberTherapy and Telemedicine, Volume 3, pp. 296-297.

[49] Côté S, Bouchard S (2005) Documenting the Efficacy of Virtual Reality Exposure with Psychophysiological and Information Processing Measures. Applied Psychophysiology and Biofeedback. 30(3): 217-232.

[50] Michaliszyn D, Marchand A, Bouchard S, Martel MO, Poirier-Bisson J (2010). A Randomized, Controlled Clinical Trial of In Virtuo and In Vivo Exposure for Spider Phobia. Cyberpsychology, Behaviour and Social Networking. 13(6): 689-695.

[51] St-Jacques J, Bouchard S, Bélanger C (2010) Is Virtual Reality Effective to Motivate and Raise Interest in Phobic Children Towards Therapy? Journal of Clinical Psychiatry, 71(7): 924-931.

[52] Thorpe SJ, Salkovskis PM (1997) The Effect of One-Session Treatment for Spider Phobia on Attentional Bias and Beliefs. British Journal of Clinical Psychology. 36: 225-241.

[53] Côté S, Bouchard S (2009) Cognitive Mechanisms Underlying Virtual Reality Exposure. Cyberpsychology \& Behaviour. 12(2): 121-129.

[54] Bouchard S, Mendlowitz SL, Coles ME, Franklin M (2004) Considerations in the Use of Exposure with Children. Cognitive and Behavioural Practice. 11(2): 56-65.

[55] Silva C, Bouchard S, Bélanger C (2011) Youths are More Apprehensive and Frightened than Adults by a Virtual EnvironmentUsed to Treat Arachnophobia. Journal of Cybertherapy and Rehabilitation. 4(2): 200-201. 
[56] Optale G, Marin S, Pastore M, Nasta A, Pianon C (2003) Male Sexual Dysfunctions and Multimedia Immersion Therapy (Follow-Up). CyberPsychology \& Behaviour. 6(3), 289294.

[57] Wiederhold BK, Gavshon L, Wiederhold MD (2010) A Psychodynamic View of Virtual Reality Exposure Therapy. Journal of CyberTherapy \& Rehabilitation. 3(4): 395-403.

[58] Cairo I, Fischbein SV (2010) Psychoanalysis and Virtual Reality. The International Journal of Psychoanalysis. 91(4): 985-988.

[59] Neubeck AK, Neubeck B (1998) Virtual Reality as a Support System for Psychodynamic Treatment. CyberPsychology \& Behaviour. 1(4): 341-345.

[60] Meyerbröker K, Emmelkamp, PMG (2008) Therapeutic Processes in Virtual Reality Exposure Therapy: The Role of Cognitions and the Therapeutic Alliance. Journal of CyberTherapy \& Rehabilitation. 1(3): 247-257. 